\title{
MMA Board Member Named Fellow of ASM International
}

Dr. Donald F. Susan, a member of the Editorial Board of Metallography, Microstructure, and Analysis, has been named a Fellow of ASM International in recognition of distinguished contributions to materials science and engineering. The 22 members of ASM's 2016 Class of Fellows were honored at the ASM Awards Dinner during MS\&T 2016 in Salt Lake City, in October.

Susan, a researcher in Sandia's Metallurgy and Materials Joining Department, was cited "For sustained contributions in the areas of physical metallurgy and joining research, materials characterization, and failure analysis."

"It's a big honor for me, especially knowing the Fellows who came before me," Susan said. "It's a big honor to follow in their footsteps."

Susan joined Sandia in 2000. His areas of expertise include hermetic connector technology, tin-lead and leadfree solder metallurgy, active brazing alloys, electrical contact alloy metallurgy, high-strength stainless steels, metallography and quantitative image analysis, and failure analysis. He is a co-inventor on work that led to a patent on glass-ceramic to metal sealing for high-temperature, highpressure applications. "I have a lot of interests and I'm glad to be recognized by ASM as a generalist in metallurgy," he said.

Susan traces his interest in materials science to his father, who worked in a Honeywell facility that made plastic film. "I guess the materials science aspect rubbed off on me, except it was metals, not polymers," commented Susan, who holds a doctorate in materials science and engineering from Lehigh University.

$\mathrm{He}$ also has worked on shape-changing alloys and was principal investigator for a 3-year project to create hightemperature shape-memory alloys. In addition, over the years he worked on numerous teams conducting materials research

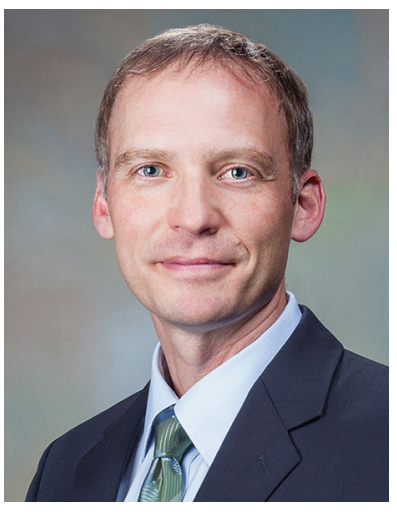

Dr. Donald F. Susan

and component evaluations to ensure the safety, security, and reliability of the nation's nuclear weapons stockpile.

He recalled a project on an iron-cobalt based alloy called Hiperco that turned out to be satisfying for him and his colleagues because they solved a problem in an unexpected way. Hiperco had poor mechanical properties, but the team found a way to increase its strength by two to three times through a process called Equal Channel Angular Extrusion, which extrudes a bar of metal in a way that can be described as going around a corner. "We were all skeptical at first, but it works," Susan said. "This was a very satisfying project because it was a bit of a surprise to all of us."

Fellows serve as advisers to ASM International to enhance its standing as a leading organization for materials and provide a resource to serve the worldwide community of materials scientists and engineers in the years ahead. The society established the honor in 1969 to recognize Fellows' contributions and to develop a broadly based forum of technical and professional leaders to be advisers. 